\title{
C-reactive protein and thyroid-stimulating hormone levels as risk factors for hypothyroidism in patients with subacute thyroiditis
}

\author{
Chenjia Tang', Yanting Dong ${ }^{1,2}$, Lusi Lu ${ }^{1}$ and Nan Zhang ${ }^{1}$ \\ ${ }^{1}$ Department of Endocrinology, Sir Run Run Shaw Hospital, School of Medicine, Zhejiang University, Hangzhou, China \\ 2Department of Endocrinology, Suichang County Hospital of Traditional Chinese Medicine, Lishui, China \\ Correspondence should be addressed to N Zhang: 3198047@zju.edu.cn
}

\begin{abstract}
Objective: This study was designed to explore the relationships between the clinical characteristics and outcomes of patients with subacute thyroiditis (SAT).

Design: This is a single-center retrospective study.

Patients: Eighty-nine patients with SAT who were hospitalized in the Sir Run Run Shaw Hospital in Zhejiang, China, from October 2014 to September 2020 were included.

Methods: The Mann-Whitney U-test, chi-square test, and Cox regression analysis were conducted to identify the relationships between clinical characteristics and outcomes. Receiver operating characteristic $(\mathrm{ROC})$ analysis was performed to determine the optimal cutoff levels of C-reactive protein (CRP) and thyroid-stimulating hormone (TSH).

Results: The hypothyroidism and recurrence rates were 15.7 and $16.9 \%$, respectively. $\mathrm{CRP}(\geq 72.0 \mathrm{mg} / \mathrm{L}), \mathrm{TSH}(<0.02 \mathrm{mIU} / \mathrm{L})$, and free triiodothyronine (fT3) $(\geq 4.10 \mathrm{pg} / \mathrm{mL})$ were associated with hypothyroidism. The cutoff level was $97.80 \mathrm{mg} / \mathrm{L}$ for CRP (area under the curve (AUC), 0.717, $P=0.014$; sensitivity, 57.1\%; specificity, $84.0 \%$ ) and $0.10 \mathrm{mIU} / \mathrm{L}$ for TSH (AUC, $0.752, P=0.004$; sensitivity, $100 \%$; specificity, $46.0 \%$ ) by ROC curve analysis for hypothyroidism. The factors under study were not associated with recurrence.

Conclusion: CRP and TSH were risk factors for hypothyroidism in SAT. Thyroid functions should be monitored closely for the early detection of hypothyroidism, especially in patients with CRP levels of more than $97.80 \mathrm{mg} / \mathrm{L}$ and TSH levels of less than $0.10 \mathrm{mIU} / \mathrm{L}$.
\end{abstract}

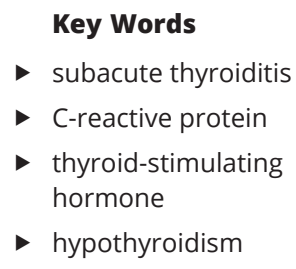

Endocrine Connections (2021) 10, 965-972

\section{Introduction}

Subacute thyroiditis (SAT), also known as De Quervain's thyroiditis, giant cell thyroiditis, or granulomatous thyroiditis, is an inflammatory thyroid disease, probably associated with viral infection (1). It is often characterized by neck pain, goiter, and systemic inflammation. Some scholars have proposed diagnostic criteria for SAT $(2,3)$. This disease is usually diagnosed according to systemic symptoms, such as acute fever, thyroid pain, and the phenomenon of significantly increased erythrocyte sedimentation rate (ESR), increased serum thyroid hormone levels, and decreased thyroid iodine uptake. However, more atypical cases, such as those without neck pain, have been reported $(4,5,6)$. Recently, Stasiak et al. have proposed new and modified diagnostic criteria for SAT (7).

Although the disease is self-limited, patients still need treatment for pain and thyroid toxicity. However, no precise therapy has been established yet. For mild 
cases, nonsteroidal anti-inflammatory drugs (NSAIDs) are available clinically. However, for patients with severe pain, NSAIDs are ineffective; instead, glucocorticoid therapies are applied. Chinese guidelines recommend an initial dose of $30 \mathrm{mg} /$ day for prednisone, but evidence-based researches were insufficient (3). Several studies have focused on the optimal doses of steroids $(8,9,10)$. Some scholars have recommended an initial treatment with lower doses of prednisolone daily $(8,9)$. One study has shown that the treatment with an initial dose of $15 \mathrm{mg}$ daily for steroids had similar efficacy and fewer adverse reactions (8). The initial dose should be maintained for approximately 1-2 weeks, and the dose should be reduced gradually when the patient's symptoms are relieved $(8,11)$.

The incidence of hypothyroidism after treatment is $5-27 \%(12,13)$, and the incidence of recurrence ranges from $1.6-20 \%(14,15)$. Many scholars have explored the risk factors for recurrence and hypothyroidism in patients with SAT. The risk of recurrence in patients with SAT was HLA-dependent, and the co-presence of HLA-B*18:01 and $-B * 35$ was a determining factor (16). Some studies have shown that patients who received corticosteroid therapy tended to receive T4 therapy, whereas some studies have shown the opposite $(13,17)$.

This study was designed to describe the clinical characteristics of SAT and explore the relationships between those clinical characteristics and the outcomes in hospitalized patients with SAT.

\section{Materials and methods}

\section{Patients and data collection}

This retrospective study included 95 Chinese patients who were diagnosed with SAT between October 2014 and September 2020 in the Department of Endocrinology and Metabolic Diseases, the Sir Run Run Shaw Hospital, School of Medicine, Zhejiang University. Three patients were excluded due to incomplete data. Additionally, three patients were excluded because they had elevated thyroid antibodies and a long interval between SAT diagnosis and outcomes. The study complies with the Declaration of Helsinki and was approved by the Ethics Committee of Sir Run Run Shaw Hospital, School of Medicine, Zhejiang University.

As in previous studies $(2,5,8)$, the inclusion criteria for the diagnosis of SAT in this study were as follows: (1) painful, tender, hard goiter often accompanied by symptoms and signs resembling an upper respiratory infection; (2) increased ESR or C-reactive protein (CRP); (3) depressed thyroid radionuclide uptake; (4) transient hyperthyroidism; and (5) hypoechoic areas with blurred margins on thyroid ultrasonography. For patients who did not meet the aforementioned criteria but were suspected of SAT, fine-needle aspiration and cytology of the thyroid were performed. Patients were considered to have SAT if histological findings were compatible with SAT. Those who had SAT with GD were excluded. Hypothyroidism was defined as free thyroxine (fT4) levels below the normal reference range and thyroid-stimulating hormone (TSH) levels above the normal reference range. Recurrence was defined based on the relapse of clinical symptoms, such as neck pain, usually accompanied by an increase in CRP or ESR.

All laboratory tests, ultrasonographic examinations, and thyroid uptake scans were performed before the patients received treatment. White blood cell (WBC) count, neutrophil (Neu) count, mean platelet volume (MPV), platelets (PLT), and lymphocytes were measured using an automatic blood analysis line (CAL-8000; Mindray Medical International Limited, Shenzhen, China). CRP was determined using immunoturbidimetry. Triiodothyronine (T3), free triiodothyronine (fT3), thyroxine (T4), fT4, $\mathrm{TSH}$, thyroid peroxidase antibody (aTPO), thyroglobulin antibody (aTG), and thyrotropin receptor antibody (TRAb) were measured using the Elecsys electrochemiluminescence immunoassay (Roche Holding AG). The thyroid volume of each lobe was calculated using the formula proposed by Brunn et al.: thyroid volume $(\mathrm{mL})=0.479 \times$ length $(\mathrm{cm}) \times$ thickness $(\mathrm{cm}) \times$ width $(\mathrm{cm})(18)$. The total volume was the sum of both lobes, excluding the isthmus. The reference ranges were as follows: WBC (3.5-9.5 × 109/L), Neu (1.8-6.3 × 109/L), MPV (6.5-13.0fL), PLT (1.10-3.20× 109/L), ESR (1-15 mm/h), CRP (0-6 mg/L), TSH (0.35-4.94 mIU/L), T4 (4.87-11.72 ug/dL), fT4 (0.70-1.48 ng/dL), T3 (0.64-1.52 $\mathrm{ng} / \mathrm{mL})$, fT3 (1.71-3.71 pg/mL), aTG (0-4.11 IU/mL), aTPO (0-5.61 IU/mL), and TRAb (0-1.22 IU/L).

\section{Statistical analysis}

All statistical analyses were performed using Statistical Package for the Social Sciences (version 24.0; IBM Corp.). Results were presented as median (range) for variables. Additionally, each quantitative variable was converted to a classified variable based on its median or medical reference range. For comparisons between groups, the Mann-Whitney $U$-test was used. Categorical variables were reported as frequencies, and relationships among them were examined using the chi-square test. Cox regression

This work is licensed under a Creative Commons Attribution-NonCommercial-NoDerivatives 4.0 Internationad License ifica com at 04/26/2023 01:09:16PM 
analysis was employed to evaluate the relationship between hypothyroidism or recurrence and variables. Receiver operating characteristic (ROC) analysis was performed to determine the optimal cutoff levels of variables by yielding the maximum sums of sensitivity and specificity from the curve. $P$-values of less than 0.05 were used to denote statistical significance.

\section{Results}

\section{The characteristics of the patients}

Eighty-nine patients with SAT, including 61 females and 28 males, were enrolled in this study. The clinical characteristics of the patients are shown in Table 1 . The median age was 50 years. The disease started in summer in $36.0 \%(32 / 89)$ of the patients and in autumn in $28.1 \%$ $(25 / 89)$ of the patients. Moreover, $82.0 \%(73 / 89)$ of the patients had a fever in the process. Then, 91.0\% (81/89) of the patients had neck pain. Among all patients, 23 females and 5 males experienced 'crawling neck pain' - neck pain from one side to the other, which was more frequent in summer and autumn than in winter and spring (64.2\% vs $35.8 \%)$. Four (50\%) of eight patients who did not have pain had SAT in spring. Hypertension was found in 19 (21.3\%) patients, diabetes mellitus was found in 18 (20.2\%) patients, and 2 patients had Hashimoto thyroiditis.

Moreover, WBC, maximum body temperature, CRP, and TSH were available for 89 patients; MPV, PLT, ESR, and $\mathrm{T} 4$ were available for 88 patients; Neu, lymphocyte and T3 were available for 87 patients; fT3, aTG, and aTPO were available for 85 patients; fT4 was available for 84 patients; TRAb was available for 62 patients. Thyroid ultrasonography was performed on every patient, whereas thyroid volume results were available for 66 patients. All patients were examined for thyroid uptake scan, and those results were found to be reduced. WBC, Neu, PLT, and ESR levels were above the normal range in 31.5\% (28/89), 40.2\% (35/87), 30.3\% (27/89), and 100\% (88/88) of the patients, respectively. Furthermore, CRP levels were within the normal range in $4.5 \%(4 / 89)$ of the patients, all of whom were female, with a medical history longer than 2 months. On the first visit to our clinic, 83.1\% (74/89) of the patients had hyperthyroidism, and $16.8 \%$ $(15 / 89)$ of them were euthyroid. Moreover, 19.1\% (17/89) of the patients showed an increase in both aTG and aTPO levels, whereas an increase in aTG or aTPO levels was observed in $64.0 \%(57 / 89)$ and $22.5 \%(20 / 89)$ of the patients, respectively. Among the patients, $22.6 \%(14 / 62)$ had elevated TRAb levels. In this study, male patients had higher Neu, CRP, and TRAb levels $(P=0.046,0.008$, and 0.014, respectively). Furthermore, patients with fever had higher Neu, PLT, CRP, TSH, T3, fT3, T4, and fT4 evels $(P<0.05)$.

\section{Therapies of the patients}

Among the 89 patients, $24.7 \%$ (22/89) were treated with NSAIDs alone, $16.9 \%(15 / 89)$ were treated with steroids alone, and 58.4\% (52/89) were treated with both NSAIDs and steroids. Diclofenac sodium and celecoxib were the most frequently used NSAIDs, accounting for 70.3\% (52/74) and $33.8 \%(25 / 74)$ of the patients, respectively. Among patients treated with steroids, $77.6 \%(52 / 67)$ received oral dosage forms, and $46.3 \%$ (31/67) received injections.

\section{Patient outcomes}

The total hypothyroidism rate in the study was $15.7 \%$. Twelve $(85.7 \%)$ of the 14 cases who had hypothyroidism occurred within 2 months of treatment, and the latest was after 166 days. Age, BMI, disease course, WBC, Neu, lymphocyte, PLT, MPV, ESR, aTG, aTPO, TRAb, thyroid volumes, the rate of fever, neck pain, and therapies were similar in the normal and hypothyroidism groups $(P>0.05)$. Significant differences in CRP, TSH, T3, fT3, T4, and fT4 levels were observed between the two groups $(P=0.014$, $0.004,0.029,0.024,0.016$, and 0.030 , respectively).

In the univariate regression analysis, CRP $(\geq 72.0 \mathrm{mg} / \mathrm{L})$, TSH $(<0.02 \mathrm{mIU} / \mathrm{L})$, and fT3 $(\geq 4.10 \mathrm{pg} / \mathrm{mL})$ were significantly associated with a higher incidence of hypothyroidism (Table 2). The cutoff level was $97.80 \mathrm{mg} / \mathrm{L}$ for CRP (area under the curve (AUC), 0.717; $P=0.014$; sensitivity, $57.1 \%$; specificity, $84.0 \%$ ) and $0.10 \mathrm{mIU} / \mathrm{L}$ for TSH (AUC, 0.752; $p=0.004$; sensitivity, 100\%; specificity, 46.0\%), determined by ROC curve analysis (Fig. 1). However, in the multivariate analysis, none of the following factors had significant associations with hypothyroidism: ESR (hazard ratio $(\mathrm{HR})=1.273 ; 95 \% \mathrm{CI}=0.371-4.371 ; P=0.702)$, CRP $\quad(\mathrm{HR}=3.608 ; \quad 95 \% \quad \mathrm{CI}=0.706-18.432 ; \quad P=0.123)$, TSH $(\mathrm{HR}=0.222 ; 95 \% \mathrm{CI}=0.043-1.142 ; P=0.072)$, fT3 $(\mathrm{HR}=1.181 ; 95 \% \mathrm{CI}=0.274-5.093 ; P=0.824)$.

The total recurrence rate in the study was $16.9 \%$. Half of the cases occurred within 2 weeks after the drugs were stopped, and the latest recurrence happened in 219 days. No significant differences in basic data, inflammatory biomarkers, thyroid volume, thyroid function tests, and treatment were found between the recurrence and nonrecurrence groups $(P>0.05)$ (Table 1$)$. However, none of the

This work is licensed under a Creative Commons Attribution-NonCommercial-NoDerivatives 4.0 Internationad bicense.ifica.com at 04/26/2023 01:09:16PM 


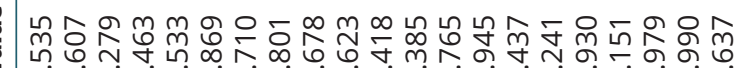

in SAT

0.00000000000000000000

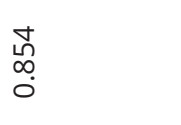

$\stackrel{\substack{N \\ 0}}{\stackrel{\bar{N}}{0}}$

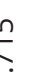

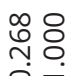

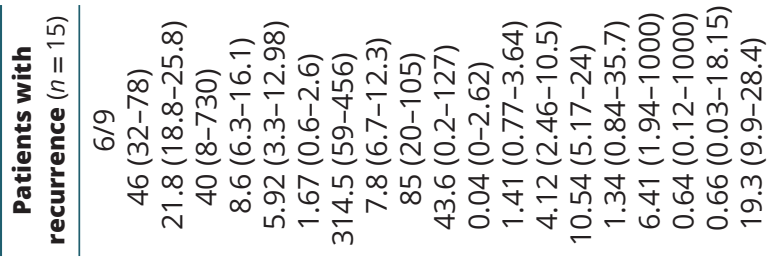

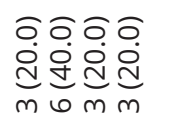

Kลำด

î

$\widehat{\kappa} \bar{m}$

$\dot{\theta} \ddot{m}$

$\forall \forall \sigma_{-}$

으

mก $\bar{n}$

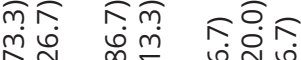

ED

$\approx+$

$\stackrel{m}{\leftarrow}$

e릴

(1)

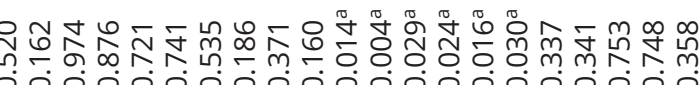

$\underset{\infty}{\infty}$

$\stackrel{\substack{m \\+}}{\circ}$

$\frac{8}{\circ}$

$\frac{\circ}{\stackrel{0}{\circ}}$

$\underset{m}{\stackrel{m}{N} \stackrel{m}{N}}$

$\underset{\substack{n \\ 0}}{\stackrel{0}{0}}$

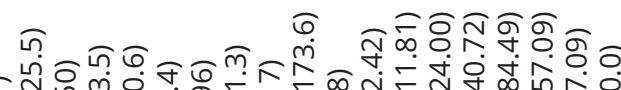

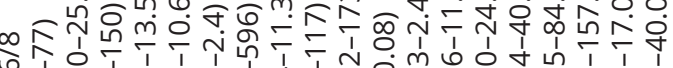

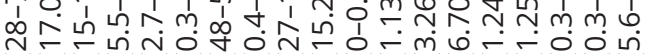

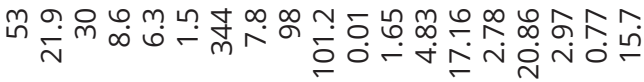

อิกิร ஹ் $\checkmark$ in $N$

สุกิ์ ثं

$\widehat{\sigma}=$

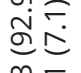

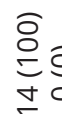
ริต กิำ 6.

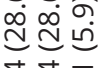

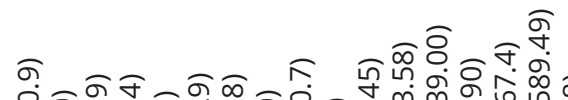

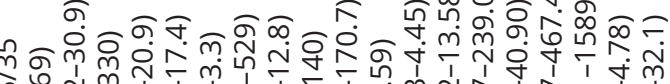

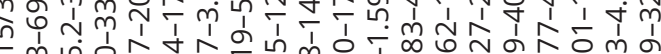
己ูป 守穴向 No

\section{oิธoิ $\dot{0} \dot{0} \dot{\square}$ $\infty 60$}

\section{oํํำ

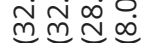 $60 \%$}

\section{$\widehat{0} \overline{0}$ $\stackrel{\infty}{\infty} \stackrel{\infty}{=}$}

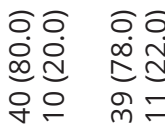

อิธ 过 $\underset{N}{ }=0$

โอิธล

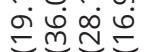
$\therefore N$ 는

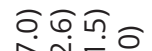

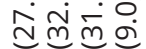
ปั $\stackrel{\infty}{\sim}$

oิ $\stackrel{\substack{\infty \\ \infty}}{\infty}$ $\stackrel{\infty}{n}=$

วิธ

๓ं

六望

$\bar{m} \hat{\kappa}$

ก럼 $\hat{6} \approx$ ตุกิ $\overline{\mathrm{c}} \stackrel{\mathrm{d}}{\mathrm{d}}$ $\stackrel{\infty}{\sim} N$ 
factors under study had a significant difference regarding recurrence in the Cox regression analysis (Table 3).

For the group receiving NSAIDs alone and the group receiving steroids alone, hypothyroidism developed in $18.2 \%(4 / 22)$ and $0 \%(0 / 15)$ of the patients, respectively, and recurrence developed in $9.1 \%(2 / 22)$ and $26.7 \%(4 / 15)$ of the patients, respectively. The 2 patients who were treated with celecoxib alone did not develop hypothyroidism or recurrence, whereas, among the 12 patients treated with diclofenac alone, 4 had hypothyroidism, and recurrence was observed in 1 patient.

\section{Discussion}

SAT is self-limited inflammatory thyroid disease, and some patients feel mild and transient discomfort, which received little attention. Unfortunately, some patients must undergo treatment because they experience severe neck pain, insomnia, and even anxiety. They may be concerned about drug efficacy, side effects, and therapeutic prognosis. In this study, we described the clinical characteristics of the hospitalized patients diagnosed with SAT, and the prognosis (hypothyroidism and recurrence) is not correlated with certain treatments. Simultaneously, we found that CRP and TSH were associated with hypothyroidism, and the cutoff levels for the two parameters were calculated.

Several studies have shown that a higher proportion of patients who had SAT were females $(12,13,19)$. In this study, the female-to-male ratio was $2.18: 1$, and $62.9 \%$ of them were in the 40-60 age range, which confirms the findings of previous studies. The increased frequency of certain types of HLA was reported in patients with SAT, and in 2020, Stasiak et al. found an association between HLA and SAT $(7,20)$. Besides, viral infection has been considered a triggering factor for SAT, such as coxsackieviruses, echoviruses, and adenoviruses $(7,21)$. Similar to the results of previous studies $(13,22,23)$, most patients had the disease in summer and autumn, which conforms to the peak of enterovirus disease incidence. In this study, male patients were more likely to have higher Neu, CRP, and TRAb levels. Neu and CRP were considered indicators of inflammation. Additionally, a similar phenomenon was found in patients with severe acute respiratory syndrome coronavirus 2 (COVID-19) infection (24). No further studies have explained this phenomenon; it might be because males have a stronger response to inflammation.

Table 2 Univariate and stepwise multivariate Cox hazard analysis of variables associated with hypothyroidism in SAT patients.

\begin{tabular}{|c|c|c|c|c|}
\hline \multirow[b]{2}{*}{ Variable } & \multicolumn{2}{|c|}{ Univariate analysis } & \multicolumn{2}{|c|}{ Multivariate analysis } \\
\hline & $\mathrm{HR}(95 \% \mathrm{Cl})$ & $P$-value & $\mathrm{HR}(95 \% \mathrm{Cl})$ & $P$-value \\
\hline Gender (male vs female) & $1.718(0.596-4.953)$ & 0.316 & & \\
\hline Age ( $\geq 50$ years vs $<50$ years) & $1.631(0.546-4.869)$ & 0.380 & & \\
\hline BMI $\left(\geq 21.26 \mathrm{~kg} / \mathrm{m}^{2}\right.$ vs $\left.<21.26 \mathrm{~kg} / \mathrm{m}^{2}\right)$ & $1.373(0.476-3.957)$ & 0.557 & & \\
\hline Course ( $\geq 30$ days vs $<30$ days) & $0.749(0.260-2.159)$ & 0.592 & & \\
\hline WBC $(\geq 8.2 \times 109 /$ L Vs $<8.2 \times 109 / L)$ & $0.973(0.341-2.775)$ & 0.960 & & \\
\hline $\mathrm{Neu}(\geq 5.9 \times 109 / \mathrm{L}$ vs $<5.9 \times 109 / \mathrm{L})$ & $1.313(0.456-3.786)$ & 0.614 & & \\
\hline Lymphocyte ( $\geq 1.6 \times 109 /$ L vs <1.6 × 109/L) & $0.859(0.301-2.450)$ & 0.777 & & \\
\hline $\operatorname{PLT}(\geq 299.0 \times 109 / L$ vs $<299.0 \times 109 / L)$ & $1.327(0.460-3.824)$ & 0.601 & & \\
\hline $\operatorname{MPV}(\geq 8.1 \mathrm{fL}$ vs $<8.1 \mathrm{fL})$ & $0.640(0.222-1.846)$ & 0.409 & & \\
\hline ESR ( $\geq 89 \mathrm{~mm} / \mathrm{h}$ vs $<89 \mathrm{~mm} / \mathrm{h})$ & $2.870(0.899-9.162)$ & $0.075^{b}$ & $1.273(0.371-4.371)$ & 0.702 \\
\hline $\mathrm{CRP}(\geq 72.0 \mathrm{mg} / \mathrm{L}$ vs $<72.0 \mathrm{mg} / \mathrm{L})$ & $4.376(1.220-15.700)$ & $0.024^{\mathrm{ab}}$ & $3.608(0.706-18.432)$ & 0.123 \\
\hline $\mathrm{TSH}(\geq 0.02 \mathrm{mlU} / \mathrm{L}$ vs $<0.02 \mathrm{mlU} / \mathrm{L})$ & $0.198(0.055-0.711)$ & $0.013^{\mathrm{ab}}$ & $0.222(0.043-1.142)$ & 0.072 \\
\hline $\mathrm{T} 3(\geq 1.36 \mathrm{ng} / \mathrm{mL}$ vs $<1.36 \mathrm{ng} / \mathrm{mL})$ & $1.915(0.642-5.716)$ & 0.244 & & \\
\hline fT3 $(\geq 4.10 \mathrm{pg} / \mathrm{mL}$ vs $<4.10 \mathrm{pg} / \mathrm{mL})$ & $3.898(1.072-14.177)$ & $0.039^{a b}$ & $1.181(0.274-5.093)$ & 0.824 \\
\hline $\mathrm{T} 4$ ( $\geq 12.35 \mathrm{ug} / \mathrm{dL}$ vs $<12.35 \mathrm{ug} / \mathrm{dL})$ & $1.891(0.634-5.645)$ & 0.253 & & \\
\hline fT4 ( $\geq 1.80 \mathrm{ng} / \mathrm{dL}$ vs $<1.80 \mathrm{ng} / \mathrm{dL})$ & $2.542(0.782-8.263)$ & 0.121 & & \\
\hline $\operatorname{aTG}(\geq 4.12 \mathrm{IU} / \mathrm{mL}$ vs $<4.12 \mathrm{IU} / \mathrm{mL})$ & $1.377(0.384-4.935)$ & 0.624 & & \\
\hline $\operatorname{aTPO}(\geq 5.62 \mathrm{IU} / \mathrm{mL}$ vs $<5.62 \mathrm{IU} / \mathrm{mL})$ & $1.100(0.345-3.507)$ & 0.872 & & \\
\hline $\operatorname{TRAb}(\geq 1.23 \mathrm{IU} / \mathrm{L}$ vs $<1.23 \mathrm{IU} / \mathrm{L})$ & $1.949(0.487-7.801)$ & 0.346 & & \\
\hline Thyroid volume $\left(\geq 16.81 \mathrm{~mm}^{3}\right.$ vs $\left.<16.81 \mathrm{~mm}^{3}\right)$ & $0.535(0.157-1.829)$ & 0.319 & & \\
\hline Steroids (yes vs no) & $0.438(0.152-1.263)$ & 0.126 & & \\
\hline
\end{tabular}

a $P<0.05$ was considered statistically significant. b Variables were included in the multivariate Cox hazard analysis if they had an univariate $P$-value $\leq 0.1$ for hypothyroidism.

aTG, thyroglobulin antibody; aTPO, thyroid peroxidase antibody; CRP, C-reactive protein; ESR, erythrocyte sedimentation rate; fT3, free triiodothyronine; fT4, free thyroxine; HR, hazard ratio; MPV, mean platelet volume; Neu, neutrophil; PLT, platelets; T3, triiodothyronine; T4, thyroxine; TRAb, thyrotropin receptor antibody; TSH, thyroid-stimulating hormone; WBC, white blood count.

https://ec.bioscientifica.com https://doi.org/10.1530/EC-21-0212 (c) 2021 The authors Published by Bioscientifica Ltd

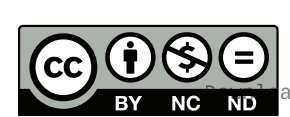

This work is licensed under a Creative Commons Attribution-NonCommercial-NoDerivatives 4.0 elfternationad dicense.ifica . com at 04/26/2023 01:09:16PM 
A

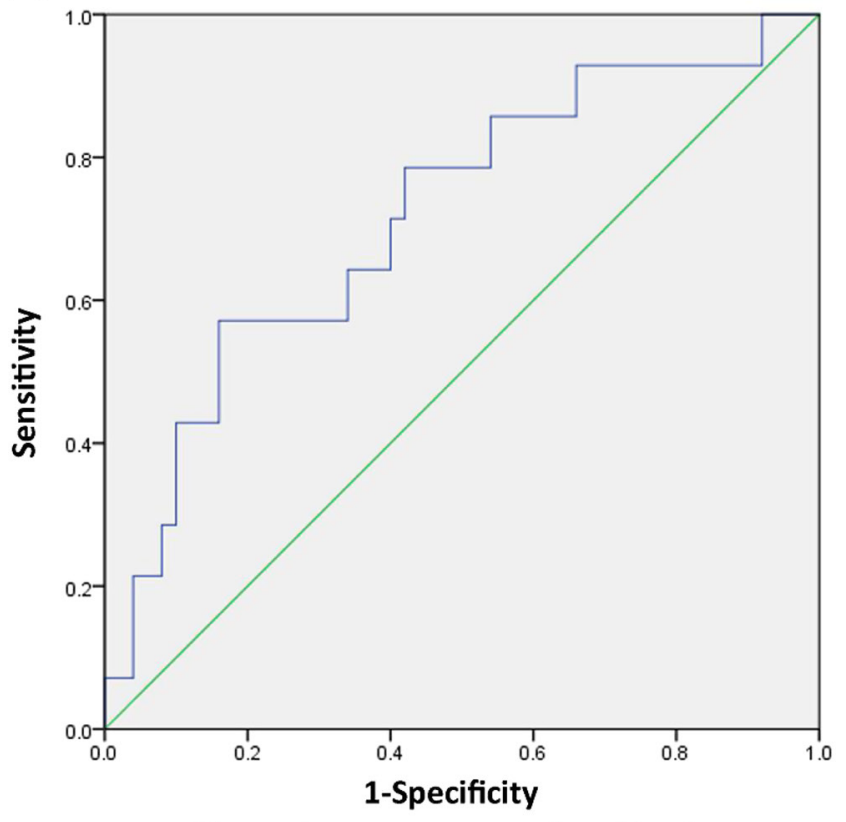

Diagonal segments are produced by ties.

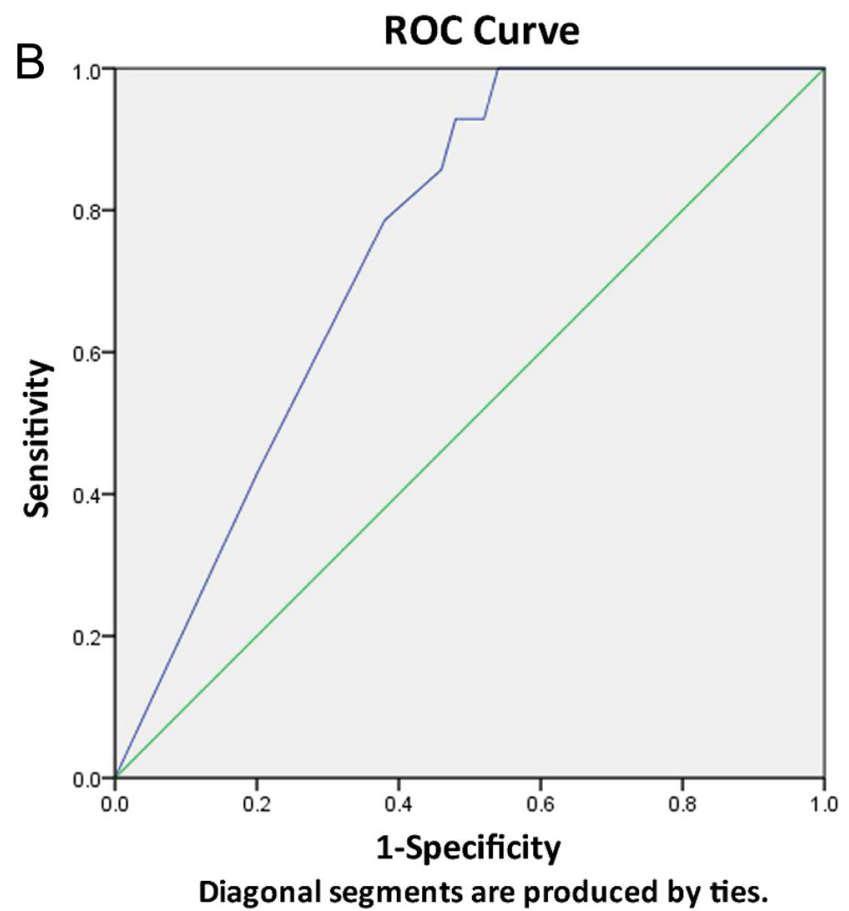

Figure 1

ROC curve analysis of CRP and TSH levels to identify a cutoff level for hypothyroidism. (A) The cutoff level for CRP was found to be $97.80 \mathrm{mg} / \mathrm{L}$ (AUC: $0.717, P: 0.014$; sensitivity: $57.1 \%$; specificity: $84.0 \%$ ) and (B) the cutoff level for TSH was found to be $0.10 \mathrm{mIU/L}$ (AUC: 0.752, P: 0.004; sensitivity: $100 \%$; specificity: $46.0 \%$ ).
Neck pain was considered the main symptom of SAT for a long time. However, recently, several painless SAT cases were reported in the literature $(5,25,26,27)$. In this study, $9.0 \%(8 / 89)$ of the patients were painless. This situation may be attributed to the development of diagnostic techniques.

Studies have reported that the incidence of hypothyroidism was $5-27 \%(12,13)$. In this study, the total hypothyroidism rate was $15.7 \%$. Patients who developed hypothyroidism had higher T3, fT3, T4, fT4, and CRP levels than the normal group, while therapies were similar in both groups. A study in the 1990s has reported that TSH receptor antibodies became positive in many patients with SAT, probably resulting in thyroid dysfunction (28). While other studies have reported female and thyroid antibody positivity as risk factors for hypothyroidism $(12,17,29)$, no statistical results could confirm the aforementioned factors in this study. Instead, CRP and TSH were found to be risk factors for hypothyroidism, especially CRP levels of more than $97.80 \mathrm{mg} / \mathrm{L}$ and TSH levels of less than $0.10 \mathrm{mIU} / \mathrm{L}$. Although fT3 $(\geq 4.10 \mathrm{pg} / \mathrm{mL})$ was associated with a higher incidence of hypothyroidism, we did not consider it due to its specific correlation with TSH. CRP is considered an inflammatory biomarker, and TSH indicates the functional status of the thyroid gland. The sensitivity of the TSH cutoff value calculated in this study was $100 \%$, possibly because these patients have severe inflammation damage and a strong inhibitory effect on thyroid function. The laboratory data we collected were all during admission when patients were at the stage of suffering from severe symptoms. Severe inflammation may significantly affect the thyroid gland, leading to hypothyroidism, which occurred in patients with SAT with high CRP and TSH levels.

Despite receiving appropriate treatments, $1.6-20 \%$ of the patients had SAT recurrence $(5,14,15,17)$. The total recurrence rate in this study was $16.9 \%$. Some studies have reported that the risk of recurrence of SAT was HLAdependent (16). Additionally, Sencar et al. have reported that recurrences were observed more frequently in patients receiving steroid therapy only than those treated with NSAIDs only (17). This trend was also found in this study, in which 4 of 15 patients treated with steroids alone had a recurrence, whereas 2 of 22 patients treated with NSAIDs alone had a recurrence. A study has reported that recurrence in patients with SAT may be due to the harmful effects of steroids on viral replication and clearance (17).

Our findings showed that patients with higher CRP and lower TSH levels were more likely to develop hypothyroidism. Closer monitoring of thyroid function

This work is licensed under a Creative Commons Attribution-NonCommercial-NoDerivatives 4.0 elnternationad dicense ifica.com at 04/26/2023 01:09:16PM 
Table 3 Univariate Cox hazard analysis of variables associated with recurrence in SAT patients.

Variable
Gender (male vs female)
Age $(\geq 49$ years vs $<49$ years $)$
BMI $\left(\geq 21.48 \mathrm{~kg} / \mathrm{m}^{2}\right.$ vs $\left.<21.48 \mathrm{~kg} / \mathrm{m}^{2}\right)$
Course $(\geq 30$ days vs $<30$ days $)$
WBC $(\geq 8.2 \times 109 / \mathrm{L}$ vs $<8.2 \times 109 / \mathrm{L})$
Neu $(\geq 5.9 \times 109 / \mathrm{L}$ vs $<5.9 \times 109 / \mathrm{L})$
Lymphocyte $(\geq 1.6 \times 109 / \mathrm{L}$ vs $<1.6 \times 109 / \mathrm{L})$
$\operatorname{PLT}(\geq 294.0 \times 109 / \mathrm{L}$ vs $<294.0 \times 109 / \mathrm{L})$
MPV $(\geq 8.2 \mathrm{fL}$ vs $<8.2 \mathrm{fL})$
ESR $(\geq 85 \mathrm{~mm} / \mathrm{h}$ vs $<85 \mathrm{~mm} / \mathrm{h})$
CRP $(\geq 66.6 \mathrm{mg} / \mathrm{L}$ vs $<66.6 \mathrm{mg} / \mathrm{L})$
TSH $(\geq 0.04 \mathrm{mIU} / \mathrm{L}$ vs $<0.04 \mathrm{mIU} / \mathrm{L})$
T3 $(\geq 1.30 \mathrm{ng} / \mathrm{mL}$ vs $<1.30 \mathrm{ng} / \mathrm{mL})$
fT3 $(\geq 3.94 \mathrm{pg} / \mathrm{mL}$ vs $<3.94 \mathrm{pg} / \mathrm{mL})$
T4 $(\geq 11.24 \mathrm{ug} / \mathrm{dL}$ vs $<11.24 \mathrm{ug} / \mathrm{dL})$
fT4 $(\geq 1.58 \mathrm{ng} / \mathrm{dL}$ vs $<1.58 \mathrm{ng} / \mathrm{dL})$
aTG $(\geq 4.12 \mathrm{IU} / \mathrm{mL}$ vs $<4.12 \mathrm{IU} / \mathrm{mL})$
aTPO $(\geq 5.62 \mathrm{IU} / \mathrm{mL}$ vs $<5.62 \mathrm{IU} / \mathrm{mL})$
TRAb $(\geq 1.23 \mathrm{IU} / \mathrm{L}$ vs $<1.23 \mathrm{IU} / \mathrm{L})$
Thyroid volume $\left(\geq 17.2 \mathrm{~cm} 3 \mathrm{vs}<17.2 \mathrm{~cm}^{3}\right)$
Steroids

\begin{tabular}{c}
\hline $\mathbf{H R}(95 \% \mathrm{Cl})$ \\
\hline $1.541(0.548-4.330)$ \\
$0.811(0.294-2.238)$ \\
$2.056(0.702-6.020)$ \\
$1.019(0.348-2.981)$ \\
$1.136(0.412-3.136)$ \\
$1.711(0.573-5.107)$ \\
$1.148(0.398-3.311)$ \\
$1.330(0.462-3.835)$ \\
$0.748(0.259-2.157)$ \\
$1.076(0.390-2.967)$ \\
$0.669(0.238-1.880)$ \\
$0.931(0.337-2.567)$ \\
$1.164(0.442-3.211)$ \\
$1.210(0.407-3.603)$ \\
$0.677(0.241-1.905)$ \\
$0.621(0.203-1.899)$ \\
$0.954(0.293-3.098)$ \\
$0.520(0.115-2.349)$ \\
$2.087(0.610-7.142)$ \\
$1.326(0.404-4.348)$ \\
$1.712(0.386-7.590)$
\end{tabular}

\begin{tabular}{c}
\hline P-value* \\
\hline 0.412 \\
0.686 \\
0.188 \\
0.973 \\
0.805 \\
0.336 \\
0.798 \\
0.597 \\
0.591 \\
0.888 \\
0.446 \\
0.890 \\
0.769 \\
0.732 \\
0.460 \\
0.404 \\
0.937 \\
0.395 \\
0.241 \\
0.642 \\
0.479
\end{tabular}

$\star P<0.05$ was considered statistically significant (variables were included in the multivariate analysis if they had an univariate $P$-value $\leq 0.1$ for hypothyroidism).

aTG, thyroglobulin antibody; aTPO, thyroid peroxidase antibody; CRP, C-reactive protein; ESR, erythrocyte sedimentation rate; fT3, free triiodothyronine; fT4, free thyroxine; HR, hazard ratio; MPV, mean platelet volume; Neu, neutrophil; PLT, platelets; T3, triiodothyronine; T4, thyroxine; TRAb, thyrotropin receptor antibody; TSH, thyroid-stimulating hormone; WBC, white blood count.

should be applied to take hormone replacement therapy in time. Besides, some patients with SAT still relapsed after receiving treatments. Although no statistical difference was found, recurrence seemed more likely to occur in patients treated with steroid therapy only.

This study has several limitations. First, it was a retrospective study. Data including the symptoms, laboratory results, and therapies in the medical records might be incomplete. Secondly, all data collected in this study were from inpatients. Most patients in the study had high inflammatory indicators or strong symptoms of discomfort at the beginning of the disease. Thus, the proportion of increased indicators, such as ESR, CRP, and Neu, was higher than that reported in other studies, which may deviate the conclusion.

\section{Conclusion}

In conclusion, this study showed that the total hypothyroidism rate was $15.7 \%$, and the total recurrence rate was $16.9 \%$. CRP and TSH were risk factors for hypothyroidism. Thyroid functions should be monitored more closely to detect hypothyroidism early, especially in patients with CRP levels of more than $97.80 \mathrm{mg} / \mathrm{L}$ and TSH levels of less than $0.10 \mathrm{mIU} / \mathrm{L}$.

\section{Declaration of interest}

The authors declare that there is no conflict of interest that could be perceived as prejudicing the impartiality of the research reported.

\section{Funding}

This work did not receive any specific grant from any funding agency in the public, commercial or not-for-profit sector.

\section{Acknowledgements}

The authors would like to acknowledge the helpful comments on this paper received from our reviewers. The authors are also grateful to Enago for polishing the English of the manuscript and thank Danying Yan for her help for submission.

\section{References}

1 Volpe R. The management of subacute (DeQuervain's) thyroiditis. Thyroid 19933 253-255. (https://doi.org/10.1089/thy.1993.3.253)

2 Iitaka M, Momotani N, Ishii J \& Ito K. Incidence of subacute thyroiditis recurrences after a prolonged latency: 24-year survey. Journal of Clinical Endocrinology and Metabolism 199681 466-469. (https://doi.org/10.1210/jcem.81.2.8636251)

3 Chinese Society of Endocrinology. Guidelines for diagnosis and treatment of thyroid diseases in China. Chinese Journal of Internal Medicine 200847 784-788.

4 Anyfantakis D, Katsanikaki F \& Kastanakis S. An elderly woman with pyrexia of unknown origin. Maedica 202015 266-268. (https://doi. org/10.26574/maedica.2020.15.2.266)

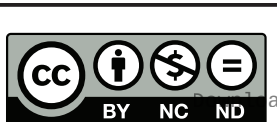

This work is licensed under a Creative Commons Attribution-NonCommercial-NoDerivatives 4.0 Internationad License ifica com at 04/26/2023 01:09:16PM 
5 Stasiak M, Michalak R, Stasiak B \& Lewinski A. Clinical characteristics of subacute thyroiditis is different than it used to be: current state based on 15 years own material. Neuro Endocrinology Letters 201939 489-495.

6 Al-Tikrity MA, Magdi M, Abou Samra AB \& Elzouki AY. Subacute thyroiditis: an unusual presentation of fever of unknown origin following upper respiratory tract infection. American Journal of Case Reports 202021 e920515. (https://doi.org/10.12659/AJCR.920515)

7 Stasiak M \& Lewiński A. New aspects in the pathogenesis and management of subacute thyroiditis. Reviews in Endocrine and Metabolic Disorders 2021 [epub]. (https://doi.org/10.1007/s11154-02109648-y)

8 Kubota S, Nishihara E, Kudo T, Ito M, Amino N \& Miyauchi A. Initial treatment with $15 \mathrm{mg}$ of prednisolone daily is sufficient for most patients with subacute thyroiditis in Japan. Thyroid 201323 269-272. (https://doi.org/10.1089/thy.2012.0459)

9 Koirala KP \& Sharma V. Treatment of acute painful thyroiditis with low dose prednisolone: a study on patients from Western Nepal. Journal of Clinical and Diagnostic Research 20159 MC01-MC03. (https:// doi.org/10.7860/JCDR/2015/14893.6427)

10 Xu S, Jiang Y, Jia A, Zhang J, Gao B, Xu J, Jing X, Jiao Y, Wei J, Xu W, et al. Comparison of the therapeutic effects of $15 \mathrm{mg}$ and $30 \mathrm{mg}$ initial dosage of prednisolone daily in patients with subacute thyroiditis: protocol for a multicenter, randomized, open, parallel control study. Trials 202021 418. (https://doi.org/10.1186/s13063-020-04337-8)

11 Arao T, Okada Y, Torimoto K, Kurozumi A, Narisawa M, Yamamoto S \& Tanaka Y. Prednisolone dosing regimen for treatment of subacute thyroiditis. Journal of UOEH 201537 103-110. (https://doi.org/10.7888/ juoeh.37.103)

12 Görges J, Ulrich J, Keck C, Müller-Wieland D, Diederich S \& Janssen OE. Long-term outcome of subacute thyroiditis. Experimental and Clinical Endocrinology and Diabetes 2020128 703-708. (https://doi. org/10.1055/a-0998-8035)

13 Fatourechi V, Aniszewski JP, Fatourechi GZ, Atkinson EJ \& Jacobsen SJ Clinical features and outcome of subacute thyroiditis in an incidence cohort: Olmsted County, Minnesota, study. Journal of Clinical Endocrinology and Metabolism 200388 2100-2105. (https://doi. org/10.1210/jc.2002-021799)

14 Nishihara E, Ohye H, Amino N, Takata K, Arishima T, Kudo T, Ito M, Kubota S, Fukata S \& Miyauchi A. Clinical characteristics of 852 patients with subacute thyroiditis before treatment. Internal Medicine 200847 725-729. (https://doi.org/10.2169/ internalmedicine.47.0740)

15 Mizukoshi T, Noguchi S, Murakami T, Futata T \& Yamashita H. Evaluation of recurrence in 36 subacute thyroiditis patients managed with prednisolone. Internal Medicine 200140 292-295. (https://doi. org/10.2169/internalmedicine.40.292)

16 Stasiak M, Tymoniuk B, Stasiak B \& Lewinski A. The risk of recurrence of subacute thyroiditis is HLA-dependent. International Journal of Molecular Sciences 201920 1089. (https://doi.org/10.3390/ ijms20051089)
17 Sencar ME, Calapkulu M, Sakiz D, Hepsen S, Kus A, Akhanli P, Unsal IO, Kizilgul M, Ucan B, Ozbek M, et al. An evaluation of the results of the steroid and non-steroidal anti-inflammatory drug treatments in subacute thyroiditis in relation to persistent hypothyroidism and recurrence. Scientific Reports 2019916899. (https://doi.org/10.1038/s41598-019-53475-w)

18 Brunn J, Block U, Ruf G, Bos I, Kunze WP \& Scriba PC. Volumetric analysis of thyroid lobes by real-time ultrasound. Deutsche Medizinische Wochenschrift 1981106 1338-1340. (https://doi. org/10.1055/s-2008-1070506)

19 Benbassat CA, Olchovsky D, Tsvetov G \& Shimon I. Subacute thyroiditis: clinical characteristics and treatment outcome in fifty-six consecutive patients diagnosed between 1999 and 2005. Journal of Endocrinological Investigation 200730 631-635. (https://doi. org/10.1007/BF03347442)

20 Stasiak M, Tymoniuk B, Michalak R, Stasiak B, Kowalski ML \& Lewiński A. Subacute thyroiditis is associated with HLA-B*18:01, -DRB ${ }^{*} 01$ and $-C^{*} 04: 01-$ the significance of the new molecular background. Journal of Clinical Medicine 20209 9. (https://doi. org/10.3390/jcm9020534)

21 Oláh R, Hajós P, Soós Z \& Winkler G. De Quervain thyroiditis: corner points of the diagnosis. Orvosi Hetilap 2014155 676-680. (https://doi. org/10.1556/OH.2014.29865)

22 Martino E, Buratti L, Bartalena L, Mariotti S, Cupini C, AghiniLombardi F \& Pinchera A. High prevalence of subacute thyroiditis during summer season in Italy. Journal of Endocrinological Investigation $198710321-323$. (https://doi.org/10.1007/BF03348138)

23 Kitchener MI \& Chapman IM. Subacute thyroiditis: a review of 105 cases. Clinical Nuclear Medicine 198914 439-442. (https://doi. org/10.1097/00003072-198906000-00010)

24 Shi MJ, Lv JG, Lin L \& Guo JY. Trends in coronavirus disease 2019 hospitalization and prognosis: gender effect. Current Medical Science 202141 312-317. (https://doi.org/10.1007/s11596-021-2348-8)

25 Dalugama C. Asymptomatic thyroiditis presenting as pyrexia of unknown origin: a case report. Journal of Medical Case Reports 201812 51. (https://doi.org/10.1186/s13256-018-1590-6)

26 Daniels GH. Atypical subacute thyroiditis: preliminary observations. Thyroid 2001 11 691-695. (https://doi.org/10.1089/105072501750362772)

27 Stasiak M, Michalak R \& Lewinski A. Thyroid primary and metastatic malignant tumours of poor prognosis may mimic subacute thyroiditis - time to change the diagnostic criteria: case reports and a review of the literature. BMC Endocrine Disorders 201919 86. (https://doi. org/10.1186/s12902-019-0415-y)

28 Iitaka M, Momotani N, Hisaoka T, Noh JY, Ishikawa N, Ishii J, Katayama S \& Ito K. TSH receptor antibody-associated thyroid dysfunction following subacute thyroiditis. Clinical Endocrinology 1998 48 445-453. (https://doi.org/10.1046/j.1365-2265.1998.00416.x)

29 Gozariu L, Stroe M, Vladutiu T, Yepez-Escobar NG, Simionescu L, Szantay I, Dumitru E \& Florescu O. Late hypothyroidism following subacute thyroiditis. Experimental and Clinical Endocrinology 198687 48-52. (https://doi.org/10.1055/s-0029-1210522)

Received in final form 15 July 2021

Accepted 21 July 2021

Accepted Manuscript published online 21 July 2021 https://ec.bioscientifica.com https://doi.org/10.1530/EC-21-0212 (c) 2021 The authors Published by Bioscientifica Ltd
This work is licensed under a Creative Commons Attribution-NonCommercial-NoDerivatives 4.0 International License . 